\title{
Intimate Partner Violence against Women Living in Inadequate Conditions in Sub-Saharan Africa: A Meta-Analysis of Demographic and Health Survey Data
}

\author{
Yaqing Gao $\mathbb{D}$, Yinping Wang, Xiaoyi Mi, Mo Zhou, Siyu Zou and Hong Zhou *(D) \\ Department of Maternal and Child Health, School of Public Health/National Health Commission Key Laboratory \\ of Reproductive Health, Peking University, Beijing 100191, China; gaoyaqing@bjmu.edu.cn (Y.G.); \\ wyping201406@bjmu.edu.cn (Y.W.); 2011210093@bjmu.edu.cn (X.M.); gaoss@pku.edu.cn (M.Z.); \\ zousiyu@pku.edu.cn (S.Z.) \\ * Correspondence: hongzhou@bjmu.edu.cn
}

check for updates

Citation: Gao, Y.; Wang, Y.; Mi, X.; Zhou, M.; Zou, S.; Zhou, H. Intimate Partner Violence against Women Living in Inadequate Conditions in Sub-Saharan Africa: A Meta-Analysis of Demographic and Health Survey Data. Int. J. Environ. Res. Public Health 2021, 18, 10138. https://doi.org/ 10.3390/ijerph181910138

Academic Editor:

Jagdish Khubchandani

Received: 29 July 2021

Accepted: 22 September 2021

Published: 27 September 2021

Publisher's Note: MDPI stays neutral with regard to jurisdictional claims in published maps and institutional affiliations.

Copyright: (c) 2021 by the authors. Licensee MDPI, Basel, Switzerland. This article is an open access article distributed under the terms and conditions of the Creative Commons Attribution (CC BY) license (https:// creativecommons.org/licenses/by/ $4.0 /$ )

\begin{abstract}
Intimate partner violence (IPV) against women is a major public health problem and is widespread in sub-Saharan Africa (SSA). However, little is known about its environmental determinants. This study aimed to investigate whether inadequate living conditions are associated with IPV victimization in women in SSA. We analyzed cross-sectional data for 102,714 women in 25 SSA countries obtained from the Demographic and Health Surveys Program. Logistic regression was used to estimate the country-specific effects of inadequate living conditions (housing with at least one of four characteristics of unimproved water, unimproved sanitation, insufficient space, and unfinished materials) on multiple forms of IPV. Random effects meta-analysis was used to combined the country-specific estimates. We found an association between inadequate living conditions and a higher likelihood of experiencing any $(\mathrm{OR}=1.12,95 \% \mathrm{CI} 1.03$ to $1.23, p=0.012)$, sexual $(\mathrm{OR}=1.18$, $95 \%$ CI 1.05 to $1.34, p=0.008)$, emotional (OR $=1.12,95 \%$ CI 1.02 to $1.23, p=0.023$ ), and physical $(\mathrm{OR}=1.15,95 \%$ CI 1.03 to $1.28, p=0.010)$ IPV. The associations were stronger for rural and lesseducated women. These findings suggest that future research to establish a causal link between living conditions and IPV and to elucidate the underlying pathways is crucial to design IPV interventions in SSA.
\end{abstract}

Keywords: inadequate living conditions; intimate partner violence; sub-Saharan Africa; metaanalysis

\section{Introduction}

Intimate partner violence (IPV) is increasingly recognized as a significant social and public health problem. Globally, almost one-third (30\%) of ever-partnered women have experienced physical and/or sexual IPV [1]. Most IPV research of risk factors and interventions focused on individual factors, such as a woman's or partner's wealth, education, and acceptance of violence and women's decision-making autonomy [1,2]. However, only a little attention has been paid to environmental determinants of IPV, such as drought [3] and armed conflict [4].

Inadequate living conditions, commonly characterized by unimproved water and sanitation, insufficient living area, and non-durable construction, are universal markers of a disadvantaged home environment [5]. Studies have revealed that inadequate living conditions are directly associated with poor health outcomes, such as injuries, infectious diseases, and malnutrition [6]. Inadequate living conditions have also been associated with depression and stress [7], which in turn may contribute to the occurrence of violence [8]. Indeed, associations of inadequate living conditions and/or its characteristics with multiple forms of violence have been documented, such as non-partner violence [9-11], homicide [12], and child abuse [13]. Thus, inadequate living conditions might also be linked to IPV 
toward women. However, few studies have investigated the direct associations between inadequate living conditions and multiple forms of IPV toward women.

Living conditions are particularly poor in sub-Saharan Africa (SSA), because of the high rate of population growth and lack of housing [14]. In 2015, 47\% (53 million) of the urban population and $82 \%$ ( 595 million) of the rural population lived in unimproved housing in SSA [5]. Houses are deemed unimproved when they have at least one of the four characteristics of unimproved water, unimproved sanitation, more than three people per bedroom, and being made of unfinished materials [5]. SSA also has a high incidence of IPV, reflecting the situation on the African continent, where $36.6 \%$ of ever-partnered women are affected by IPV [1]. The association between inadequate living conditions and different forms of IPV merits examination in a multi-country setting, such as SSA.

In the present study, we used data collected by the Demographic and Health Surveys (DHS) Program [15] from 25 countries in SSA to test the hypothesis that, for married or cohabiting women, inadequate living conditions are associated with a higher likelihood of experiencing emotional, physical, and/or sexual violence. We conducted stratified analyses by residence type (rural/urban) and education level (less than secondary/secondary or higher education) of the respondent, which could help design targeted screening and interventions for vulnerable groups.

\section{Materials and Methods}

\subsection{Data Source}

DHS are cross-sectional surveys with a focus on households in low- and middleincome countries (LMICs), and provide nationally representative data on demography, reproductive health, and child health [15]. We selected DHS conducted in SSA countries that (1) included information on the housing environment; (2) assessed IPV using the standard questionnaire in the domestic violence module; and (3) were publicly available before July 2021. For countries that had completed multiple rounds of the DHS, we selected the most recent survey data as they represent the latest situation of that country.

The surveys use a randomized multi-stage cluster-sampling design. In the first stage, clusters are selected with probability being proportional to cluster size, which is defined by the national population census. In the second stage, a predetermined number (approximately 25-30) of households are randomly sampled within each cluster. The target population is all women aged 15 to 49 years. Information on IPV is collected from one woman who is randomly selected among all the eligible women within each household. We restricted our sample to women who provided information on IPV and were currently married or cohabiting with a male partner.

\subsection{Outcomes}

The DHS contains the domestic violence module, which was developed according to the guideline set out by the World Health Organization (WHO) on the ethical collection of such sensitive information [16]. The IPV questionnaire in the module is modified from the Conflict Tactics Scales, which has good validity and reliability [17]. The questionnaire includes questions that ask women whether their current or most recent (if divorced, separated, or widowed) husband/partner ever perpetrated any of a number of behaviorally specific acts of violence and the frequency of perpetration in the 12 months preceding the interview.

The IPV questionnaire assesses sexual, emotional, and physical violence. Supplementary Text S1 presents the complete IPV questionnaire. If a woman reported experiencing at least one of the acts belonging to a form of IPV in the past 12 months, she is defined as having experienced a specific form of IPV. "Any IPV" was defined by as the experience of any form of IPV in the past 12 months [18]. We selected all three forms of IPV and "any IPV" as outcomes. 


\subsection{Exposures}

Based on the definition of a slum household proposed by the United Nations [19], we defined inadequate living conditions as housing lacking any one of the following characteristics: durable construction, improved water, improved sanitation, and sufficient living space. The definition is consistent with previous studies that assessed the association of housing with child physical and mental health in LMICs [20-22].

We used the quality of building materials as a proxy for a house's durability. If the material of more than one out of three components of its floor, roof, and wall could be classified as "unfinished" based on the DHS criteria (Supplementary Table S2), then the house's building material was considered as unfinished $[5,20]$. We classified the household access to water and sanitation as 'improved' and 'unimproved' using the WHO and the United Nations definition (Supplementary Table S3) [23]. A house provides insufficient living space if more than three usual residents shared the room for sleeping [5].

\subsection{A Priori Confounding Variables}

The following covariates were included to control for the confounding bias: household wealth quintiles, residence type (rural/urban), age and education of the respondent, age of the respondent's partner, respondent's marital (married/cohabiting) and employment (employed/not employed) status, whether the age at the start of the first marriage or union of the respondent was less than 18 years (yes/no), and whether the partner consumes alcohol (yes/no).

Age was categorized into 15-19, 20-29, 30-39, and 40-49 years for the respondent and categorized into 15-19, 20-29, 30-39, 40-49, 50-59, and 60+ years for her partner. Education was categorized as "no education", "primary education", "secondary education", and "higher education", based on the highest education level achieved by the respondent. We defined cohabiting women as those currently living with unmarried partners, and employed women as those currently working, at the time of the interview. DHS generates wealth quintiles for all respondents based on their household ownership of a number of assets using principal component analysis [24].

\subsection{Statistical Analysis}

We conducted multivariate logistic regression to assess the association between inadequate living conditions and IPV in each country, adjusted for a priori confounding variables. The outcome of interest was each of the three forms of IPV and any IPV, and the exposures were one of the four inadequate living condition characteristics and inadequate living conditions as a combined variable. Then, for each of the four outcomes in each country, we included all four inadequate living condition characteristics in a single model and examined every characteristic's coefficients, which allows interactions between these characteristics to be taken into account.

We used the $\mathrm{I}^{2}$ index to measure the consistency of the estimates across countries [25], and the DerSimonian and Laird method for meta-analyses with random effects to pool the estimates for all countries [26].

To reveal the heterogeneities in the effect of inadequate living conditions on IPV, we stratified our analyses by residence type (rural/urban) and education level (less than secondary/secondary or higher education) of the respondent, adjusted for all a priori confounding variables except for the stratifying variable. We then pooled the results using random effects meta-analyses.

The proportion of missing data is below 3\% for all variables in all countries (Supplementary Table S4). Given the small proportion of missing data and a missing at random assumption, the estimation bias would be allowable if we ignored the missing data [27] Therefore, only data from respondents without missing information on exposures, outcomes, and confounding variables were included in the analyses. We considered the complex sample design of DHS (stratification, clustering, and survey weights for the domestic violence module) when we estimated the standard errors. 
The results were considered as statistically significant at a $p$-value lower than 0.05 . We used R version 3.6.1 (R Foundation, Vienna, Austria) for all analyses.

\section{Results}

\subsection{Study Population}

Data were extracted from surveys in 25 countries dating from 2008 to 2020. Complete outcomes, covariates, and exposure data were available for 102,714 women (Table 1). The median of the country-specific mean age of the women was 31.7 years, and that of their partners was 39.0 years. More than half of the women had less than secondary education in 22 out of the 25 countries. The percentage of unemployed women ranged from $11.1 \%$ in Ghana to $67.2 \%$ in Ethiopia. The highest proportion of women who were married or in a union before the age of 18 years was found in Chad (76.4\%), followed by Ethiopia (62.3\%) and Mali (61.0\%).

Table 1. Demographic characteristics of the study participants.

\begin{tabular}{|c|c|c|c|c|c|c|c|c|c|c|}
\hline Country & $\begin{array}{c}\text { Survey } \\
\text { Year }\end{array}$ & $\begin{array}{c}\text { Total } \\
\text { Sample } \\
(N)^{a}\end{array}$ & $\begin{array}{l}\text { Mean Age } \\
\text { (Years) }\end{array}$ & $\begin{array}{l}\text { Partner's Mean } \\
\text { Age (Years) }\end{array}$ & $\begin{array}{l}\text { Education } \\
(\%)^{c}\end{array}$ & $\begin{array}{c}\text { Cohabiting } \\
(\%)\end{array}$ & $\begin{array}{l}\text { Unemployed } \\
(\%)\end{array}$ & $\begin{array}{l}\text { Married/in Union } \\
\text { before Age } 18(\%)\end{array}$ & $\begin{array}{l}\text { Alcohol } \\
(\%)^{d}\end{array}$ & $\begin{array}{c}\text { Rural } \\
(\%)\end{array}$ \\
\hline Angola & 2015-2016 & 6578 & 30.9 & 37.8 & 67.4 & 79.6 & 24.9 & 42.2 & 40.9 & 36.4 \\
\hline Benin & 2017-2018 & 4106 & 31.7 & 38.9 & 84.6 & 21.1 & 16.1 & 41.2 & 27.2 & 60.8 \\
\hline Burundi & 2016-2017 & 6359 & 32.2 & 37.9 & 89.1 & 26.7 & 12.6 & 26.4 & 67.1 & 89.8 \\
\hline DRC & 2013-2014 & 4952 & 30.7 & 37.5 & 61.3 & 26.5 & 23.5 & 51.0 & 49.6 & 68.2 \\
\hline Cameroon & 2018 & 3852 & 31.0 & 40.8 & 60.3 & 22.1 & 30.3 & 47.5 & 45.2 & 52.5 \\
\hline Ethiopia & 2016 & 4062 & 31.3 & 39.0 & 89.2 & 2.1 & 67.2 & 62.3 & 29.4 & 83.9 \\
\hline Gabon & 2012 & 3355 & 32.3 & 40.7 & 32.2 & 63.6 & 45.8 & 31.5 & 60.4 & 12.9 \\
\hline Ghana & 2008 & 1552 & 32.5 & 40.3 & 51.5 & 21.4 & 11.1 & 39.0 & 36.4 & 58.2 \\
\hline Gambia & 2019-2020 & 1768 & 32.1 & 43.9 & 63.3 & 0.4 & 40.3 & 44.5 & 1.6 & 31.1 \\
\hline Kenya & 2014 & 3701 & 31.7 & 38.5 & 64.9 & 8.7 & 30.0 & 34.1 & 33.6 & 61.3 \\
\hline Comoros & 2012 & 2230 & 31.1 & 41.4 & 64.6 & 9.2 & 58.3 & 40.0 & 2.0 & 67.6 \\
\hline Liberia & 2019-2020 & 1958 & 32.8 & 39.2 & 65.6 & 50.8 & 28.5 & 43.3 & 39.9 & 46.2 \\
\hline Mali & 2018 & 3202 & 30.4 & 41.4 & 85.3 & 0.5 & 41.4 & 61.0 & 3.7 & 78.1 \\
\hline Malawi & 2015-2016 & 4590 & 30.2 & 35.6 & 78.2 & 6.6 & 32.8 & 51.2 & 29.0 & 83.3 \\
\hline Mozambique & 2011 & 4828 & 30.3 & 36.5 & 87.6 & 33.8 & 57.6 & 52.1 & 38.3 & 70.3 \\
\hline Nigeria & 2018 & 8231 & 32.0 & 42.0 & 58.0 & 3.8 & 28.7 & 50.6 & 22.0 & 57.0 \\
\hline Namibia & 2013 & 1111 & 33.5 & 38.8 & 28.6 & 43.6 & 48.8 & 16.6 & 56.1 & 42.3 \\
\hline $\begin{array}{l}\text { Sierra } \\
\text { Leone }\end{array}$ & 2019 & 3785 & 32.4 & 42.4 & 74.2 & 6.3 & 18.7 & 44.8 & 17.2 & 64.2 \\
\hline Senegal & 2019 & 1355 & 31.8 & 42.9 & 84.1 & 0.0 & 51.3 & 38.6 & 1.4 & 58.5 \\
\hline Chad & 2014-2015 & 3128 & 30.0 & 40.2 & 89.1 & 9.4 & 52.9 & 76.4 & 31.0 & 81.2 \\
\hline Togo & 2013-2014 & 4719 & 32.4 & 40.2 & 76.2 & 21.3 & 17.5 & 36.0 & 46.5 & 60.9 \\
\hline Tanzania & 2015-2016 & 6251 & 31.7 & 38.7 & 84.7 & 27.8 & 20.8 & 42.2 & 31.0 & 68.7 \\
\hline Uganda & 2016 & 6273 & 30.6 & 36.8 & 72.4 & 49.9 & 20.4 & 47.0 & 41.3 & 77.5 \\
\hline Zambia & 2018 & 6016 & 31.6 & 37.6 & 60.7 & 0.9 & 48.2 & 46.5 & 35.8 & 60.0 \\
\hline Zimbabwe & 2015 & 4752 & 31.5 & 38.1 & 31.7 & 4.6 & 55.8 & 36.7 & 38.3 & 65.8 \\
\hline Total $^{\mathrm{e}}$ & - & 102,714 & 31.7 & 39.0 & 67.4 & 21.1 & 30.3 & 43.3 & 35.8 & 61.3 \\
\hline
\end{tabular}

${ }^{a}$ Number of women without missing information on exposures, outcomes, and confounding variables. ${ }^{b}$ Mean or percentage of the confounding variables considering the complex sample design of DHS (stratification, clustering, and survey weights for the domestic violence module). ${ }^{\mathrm{c}}$ Percentage of women who had less than secondary education. ${ }^{\mathrm{d}}$ Percentage of women whose partners consume alcohol.

${ }^{\mathrm{e}}$ Median of the mean or the percentage of the confounding variables of all countries. DRC, Democratic Republic of the Congo.

\subsection{Characteristics of Living Conditions and Intimate Partner Violence 3.2.1. Living Conditions}

More than half of the women lived in inadequate living conditions in all countries, except for Gabon and Gambia. The median percentage of the women living in inadequate living conditions was 74.2\%. In Ethiopia (94.5\%), Chad (93.6\%), and Democratic Republic of the Congo (DRC) (91.8\%), the percentages were $>90 \%$ (Table 2). The median percentage of the women living in housing with unfinished material, unimproved water, unimproved sanitation, and insufficient room was $36.6 \%, 28.4 \%, 49.5 \%$, and $27.8 \%$, respectively. Ethiopia, Chad, and Mozambique had the highest percentage of the women who lived in housing with unfinished material $(84.8 \%, 77.4 \%$, and $76.2 \%$, respectively), as well as the highest percentage of women who did not have access to improved sanitation $(86.6 \%, 84.9 \%$, and $72.9 \%$, respectively). More than half of the women lived in housing with unimproved water only in DRC (51.6\%). Crowdedness was particularly severe in Ethiopia (61.6\%), Chad (41.6\%), and Angola (38.4\%). 
Table 2. Characteristics of living conditions of the study participants.

\begin{tabular}{|c|c|c|c|c|c|c|}
\hline Country & $\begin{array}{l}\text { Total Sample } \\
(N)^{a}\end{array}$ & $\begin{array}{l}\text { Inadequate Living } \\
\text { Conditions (\%) }\end{array}$ & $\begin{array}{l}\text { Unfinished } \\
\text { Material (\%) }\end{array}$ & $\begin{array}{l}\text { Unimproved } \\
\text { Water (\%) }\end{array}$ & $\begin{array}{c}\text { Unimproved } \\
\text { Sanitation }(\%)\end{array}$ & $\begin{array}{c}\text { Insufficient } \\
\text { Room (\%) }\end{array}$ \\
\hline Angola & 6578 & 68.2 & 44.3 & 32.0 & 32.4 & 38.4 \\
\hline Benin & 4106 & 81.5 & 27.9 & 29.9 & 68.5 & 32.9 \\
\hline Burundi & 6359 & 74.4 & 45.5 & 17.2 & 49.5 & 19.1 \\
\hline DRC & 4952 & 91.8 & 74.8 & 51.6 & 60.5 & 36.8 \\
\hline Cameroon & 3852 & 66.2 & 37.1 & 27.3 & 43.4 & 27.2 \\
\hline Ethiopia & 4062 & 94.5 & 84.8 & 37.0 & 86.6 & 61.6 \\
\hline Gabon & 3355 & 47.9 & 1.1 & 7.3 & 33.4 & 22.5 \\
\hline Ghana & 1552 & 63.3 & 20.1 & 14.0 & 34.4 & 35.1 \\
\hline Gambia & 1768 & 48.5 & 7.1 & 7.2 & 32.9 & 18.3 \\
\hline Kenya & 3701 & 80.3 & 61.2 & 29.6 & 51.0 & 38.1 \\
\hline Comoros & 2230 & 77.0 & 14.6 & 9.9 & 63.2 & 26.3 \\
\hline Liberia & 1958 & 74.5 & 36.5 & 16.6 & 54.2 & 29.2 \\
\hline Mali & 3202 & 71.2 & 49.0 & 29.7 & 42.0 & 22.2 \\
\hline Malawi & 4590 & 68.3 & 55.1 & 12.7 & 16.7 & 25.4 \\
\hline Mozambique & 4828 & 88.5 & 76.2 & 49.4 & 72.9 & 27.8 \\
\hline Nigeria & 8231 & 70.3 & 23.0 & 28.4 & 45.1 & 34.0 \\
\hline Namibia & 1111 & 60.5 & 31.1 & 11.6 & 50.8 & 20.1 \\
\hline Sierra Leone & 3785 & 71.7 & 36.6 & 35.8 & 49.5 & 18.8 \\
\hline Senegal & 1355 & 50.8 & 16.5 & 15.0 & 25.2 & 26.6 \\
\hline Chad & 3128 & 93.6 & 77.4 & 42.1 & 84.9 & 41.6 \\
\hline Togo & 4719 & 77.5 & 19.4 & 35.6 & 61.3 & 33.9 \\
\hline Tanzania & 6251 & 75.3 & 32.9 & 38.8 & 66.0 & 24.3 \\
\hline Uganda & 6273 & 81.8 & 49.6 & 21.3 & 64.5 & 37.2 \\
\hline Zambia & 6016 & 74.2 & 43.5 & 28.4 & 45.6 & 35.5 \\
\hline Zimbabwe & 4752 & 55.8 & 23.3 & 22.5 & 35.4 & 22.8 \\
\hline Total $^{\mathrm{c}}$ & 102,714 & 74.2 & 36.6 & 28.4 & 49.5 & 27.8 \\
\hline
\end{tabular}

${ }^{a}$ Number of women without missing information on exposures, outcomes, and confounding variables. ${ }^{b}$ Percentage of the inadequate living conditions and its characteristics. ${ }^{c}$ Median of the percentage of the inadequate living conditions and its characteristics of all countries. DRC, Democratic Republic of the Congo.

\subsubsection{Intimate Partner Violence}

The median prevalence of any, emotional, physical, and sexual IPV toward the women was as follows: any $32.5 \%$ (ranging from $7.6 \%$ in Comoros to $50.9 \%$ in Sierra Leone), emotional $24.7 \%$ (ranging from $5.7 \%$ in Comoros to $39.2 \%$ in Sierra Leone), physical $18.1 \%$ (ranging from 3.9\% in Comoros to 38.9\% in Sierra Leone), and sexual 6.4\% (ranging from $1.1 \%$ in Comoros to $19.8 \%$ in Burundi) (Table 3 ).

Table 3. Percentage of the study participants experiencing intimate partner violence over the past 12 months in each country included in the analysis.

\begin{tabular}{|c|c|c|c|c|c|}
\hline Country & Total Sample $(N)^{a}$ & Any (\%) $b$ & Emotional (\%) ${ }^{c}$ & Physical (\%) d & Sexual (\%) ${ }^{e}$ \\
\hline Angola & 6578 & 33.7 & 23.9 & 23.9 & 6.2 \\
\hline Benin & 4106 & 32.5 & 29.5 & 11.0 & 5.6 \\
\hline Burundi & 6359 & 33.8 & 17.2 & 18.9 & 19.8 \\
\hline DRC & 4952 & 43.3 & 28.8 & 29.8 & 18.8 \\
\hline Cameroon & 3852 & 31.2 & 22.4 & 19.3 & 6.1 \\
\hline Ethiopia & 4062 & 26.9 & 20.2 & 17.1 & 7.6 \\
\hline Gabon & 3355 & 40.4 & 27.0 & 29.1 & 11.2 \\
\hline Ghana & 1552 & 34.2 & 29.8 & 16.9 & 4.6 \\
\hline Gambia & 1768 & 17.8 & 14.3 & 8.8 & 2.2 \\
\hline Kenya & 3701 & 33.1 & 23.8 & 22.2 & 9.4 \\
\hline Comoros & 2230 & 7.6 & 5.7 & 3.9 & 1.1 \\
\hline Liberia & 1958 & 47.0 & 35.7 & 35.0 & 7.2 \\
\hline Mali & 3202 & 34.4 & 28.4 & 18.1 & 7.7 \\
\hline Malawi & 4590 & 32.3 & 22.5 & 15.4 & 14.8 \\
\hline Mozambique & 4828 & 40.2 & 30.0 & 25.7 & 6.4 \\
\hline
\end{tabular}


Table 3. Cont.

\begin{tabular}{cccccc}
\hline Country & ${\text { Total Sample }(\boldsymbol{N})^{\mathbf{a}}}$ & Any (\%) $^{\mathbf{b}}$ & Emotional (\%) $^{\mathbf{c}}$ & Physical (\%) $^{\mathbf{d}}$ & Sexual (\%) $^{\mathbf{e}}$ \\
\hline Nigeria & 8231 & 29.7 & 27.0 & 11.4 & 4.3 \\
Namibia & 1111 & 26.9 & 20.4 & 17.8 & 5.9 \\
Sierra Leone & 3785 & 50.9 & 39.2 & 38.9 & 5.8 \\
Senegal & 1355 & 9.3 & 6.1 & 4.7 & 3.0 \\
Chad & 3128 & 22.9 & 15.9 & 15.3 & 6.2 \\
Togo & 4719 & 28.0 & 25.1 & 10.5 & 4.8 \\
Tanzania & 6251 & 48.1 & 27.9 & 26.9 & 9.0 \\
Uganda & 6273 & 32.3 & 30.7 & 22.7 & 16.1 \\
Zambia & 6016 & 31.2 & 22.3 & 20.8 & 7.7 \\
Zimbabwe & 4752 & 32.5 & 24.7 & 15.7 & 6.4 \\
Total & 102,714 & & 18.1 & 6.4 \\
\hline
\end{tabular}

${ }^{a}$ Number of women without missing information on exposures, outcomes, and confounding variables. ${ }^{b}$ Estimates of the percentage of the women who had experienced emotional IPV in the previous 12 months. ${ }^{c}$ Estimates of the percentage of the women who had experienced physical IPV in the previous 12 months. ${ }^{\mathrm{d}}$ Estimates of the percentage of the women who had experienced sexual IPV in the previous 12 months. ${ }^{e}$ Estimates of the median of the percentage of the characteristics of all countries. DRC, Democratic Republic of the Congo.

\subsection{Association of Inadequate Living Conditions with Intimate Partner Violence}

After adjusting for a priori confounding variables, we found inadequate living conditions to be independently associated with a higher likelihood of experiencing any $(\mathrm{OR}=1.12,95 \% \mathrm{CI} 1.03$ to $1.23, p=0.012)$, sexual (OR $=1.18,95 \%$ CI 1.05 to $1.34, p=0.008)$, emotional (OR $=1.12,95 \%$ CI 1.02 to $1.23, p=0.023)$, and physical $(\mathrm{OR}=1.15,95 \%$ CI 1.03 to $1.28, p=0.010)$ IPV in the past 12 months (Table 4 ).

Positive and significant associations between inadequate living conditions and IPV were demonstrated in six countries for any IPV, three countries for sexual IPV, four countries for emotional IPV, and four countries for physical IPV (Supplementary Tables S5-S8). In Uganda, inadequate living conditions were associated with all three forms of IPV and any IPV. In Nigeria, inadequate living conditions were protective for all outcomes, except for sexual IPV. In Mali, inadequate living conditions were protective for emotional and any IPV.

Similar associations were found between insufficient space and any $(\mathrm{OR}=1.10$, $95 \%$ CI 1.03 to $1.18, p=0.004)$, sexual ( $\mathrm{OR}=1.12,95 \%$ CI 1.01 to $1.23, p=0.030)$, emotional (OR $=1.12,95 \%$ CI 1.06 to $1.20, p<0.001)$, and physical (OR $=1.11,95 \%$ CI 1.03 to $1.19, p=0.007)$ IPV. Unimproved sanitation was associated with a $10 \%$ increase in the odds of experiencing physical IPV (OR $=1.10,95 \%$ CI 1.01 to $1.20, p=0.024)$. Unimproved water was associated with a $9 \%$ increase in the odds of experiencing any $(\mathrm{OR}=1.09,95 \% \mathrm{CI} 1.02$ to $1.17, p=0.012$ ) and emotional (OR $=1.09,95 \%$ CI 1.03 to $1.16, p=0.005$ ) IPV.

The association between a specific characteristic of inadequate living conditions and IPV persisted after the additional adjustment for the other three characteristics, and the estimates were almost identical to those in the analyses that only adjusted for a priori confounding variables (Supplementary Table S9).

The association between inadequate living conditions and IPV was stronger among rural women and women with lower education levels (Table 5). Inadequate living conditions were associated with an increase in the odds of experiencing emotional (OR $=1.13$, $95 \%$ CI 1.01 to $1.27, p=0.034$ ), physical (OR $=1.12,95 \%$ CI 1.01 to $1.24, p=0.025)$, and any $(\mathrm{OR}=1.13,95 \% \mathrm{CI} 1.02$ to $1.25, p=0.020) \mathrm{IPV}$ in rural women, but not in urban women. Women with less than secondary education who lived in inadequate living conditions had a higher risk of experiencing sexual $(\mathrm{OR}=1.20,95 \% \mathrm{CI} 1.02$ to $1.41, p=0.031)$, emotional $(\mathrm{OR}=1.13,95 \% \mathrm{CI} 1.00$ to $1.27, p=0.043)$, and any ( $\mathrm{OR}=1.12,95 \% \mathrm{CI} 1.01$ to $1.25, p=0.026)$ IPV. Among women with secondary or higher education, inadequate living conditions were associated only with experiencing physical IPV ( $\mathrm{OR}=1.16,95 \%$ CI 1.00 to $1.34, p=0.047)$. 
Table 4. Associations of housing characteristics with intimate partner violence.

\begin{tabular}{|c|c|c|c|}
\hline Associations & OR $(95 \% \mathrm{CI})$ & $p$-Value & $I^{2}(\%)$ \\
\hline \multicolumn{4}{|c|}{ Unfinished material } \\
\hline Sexual IPV & 1.14 (0.99 to 1.32$)$ & 0.070 & 51.7 \\
\hline Emotional IPV & $1.04(0.96$ to 1.14$)$ & 0.323 & 38.2 \\
\hline Physical IPV & 1.06 (0.95 to 1.17$)$ & 0.287 & 47.4 \\
\hline Any IPV & 1.07 (0.99 to 1.16$)$ & 0.099 & 42.3 \\
\hline \multicolumn{4}{|l|}{ Unimproved water } \\
\hline Sexual IPV & 1.07 (0.97 to 1.18$)$ & 0.164 & 34.8 \\
\hline Emotional IPV & 1.09 (1.03 to 1.16$)$ & 0.005 & 23.9 \\
\hline Physical IPV & $1.06(0.98$ to 1.15$)$ & 0.157 & 48.4 \\
\hline Any IPV & 1.09 (1.02 to 1.17$)$ & 0.012 & 45.0 \\
\hline \multicolumn{4}{|c|}{ Unimproved sanitation } \\
\hline Sexual IPV & 1.02 (0.91 to 1.14$)$ & 0.734 & 43.2 \\
\hline Emotional IPV & 1.07 (0.97 to 1.17$)$ & 0.159 & 59.7 \\
\hline Physical IPV & $1.10(1.01$ to 1.20$)$ & 0.024 & 51.6 \\
\hline Any IPV & 1.08 (1.00 to 1.17$)$ & 0.063 & 57.6 \\
\hline \multicolumn{4}{|l|}{ Insufficient space } \\
\hline Sexual IPV & 1.12 (1.01 to 1.23$)$ & 0.030 & 47.0 \\
\hline Emotional IPV & 1.12 (1.06 to 1.20$)$ & $<0.001$ & 44.8 \\
\hline Physical IPV & $1.11(1.03$ to 1.19$)$ & 0.007 & 50.8 \\
\hline Any IPV & $1.10(1.03$ to 1.18$)$ & 0.004 & 57.6 \\
\hline \multicolumn{4}{|c|}{ Inadequate living conditions } \\
\hline Sexual IPV & 1.18 (1.05 to 1.34$)$ & 0.008 & 30.7 \\
\hline Emotional IPV & $1.12(1.02$ to 1.23$)$ & 0.023 & 52.8 \\
\hline Physical IPV & 1.15 (1.03 to 1.28$)$ & 0.010 & 53.2 \\
\hline Ány IPV & 1.12 (1.03 to 1.23$)$ & 0.012 & 56.4 \\
\hline
\end{tabular}

OR, odds ratio; CI, confidence interval; IPV, intimate partner violence.

Table 5. Stratified associations of inadequate living conditions with intimate partner violence.

\begin{tabular}{cccc}
\hline Associations & OR $(\mathbf{9 5} \%$ CI) & $p$-Value & $\mathbf{I}^{\mathbf{2}} \mathbf{( \% )}$ \\
\hline Rural & & & \\
Sexual IPV & $1.19(1.00$ to 1.43$)$ & 0.051 & 28.5 \\
Emotional IPV & $1.13(1.01$ to 1.27$)$ & 0.034 & 31.0 \\
Physical IPV & $1.12(1.01$ to 1.24$)$ & 0.025 & 0.0 \\
Any IPV & $1.13(1.02$ to 1.25$)$ & 0.020 & \\
\hline Urban & & & 32.4 \\
Sexual IPV & $1.11(0.94$ to 1.32$)$ & 0.212 & 50.1 \\
Emotional IPV & $1.10(0.97$ to 1.24$)$ & 0.133 & 55.7 \\
Physical IPV & $1.13(0.98$ to 1.31$)$ & 0.086 & 60.4 \\
Any IPV & $1.11(0.97$ to 1.26$)$ & 0.125 & 30.8 \\
\hline Less than secondary education & & & 34.3 \\
Sexual IPV & $1.20(1.02$ to 1.41$)$ & 0.031 & 40.4 \\
Emotional IPV & $1.13(1.00$ to 1.27$)$ & 0.043 & \\
Physical IPV & $1.13(1.00$ to 1.27$)$ & 0.052 & 0.0 \\
Any IPV & $1.12(1.01$ to 1.25$)$ & 0.026 & 26.7 \\
Sexual IPV & & & 39.6 \\
Emotional IPV & $1.12(0.97$ to 1.30$)$ & 0.120 & 33.2 \\
Physical IPV & $1.09(0.97$ to 1.22$)$ & 0.156 &
\end{tabular}




\section{Discussion}

According to our literature search, the present research is the first multi-country study to examine the association between inadequate living conditions and IPV. Overall, we found that inadequate living conditions were associated with $13 \%$ higher odds of any IPV, $19 \%$ higher odds of sexual IPV, $12 \%$ higher odds of emotional IPV, and $15 \%$ higher odds of physical IPV. We also found that insufficient space was individually associated with experiencing one or more forms of IPV. The magnitudes of associations of unimproved water and unimproved sanitation with IPV were weak, although some were statistically significant. There were no statistically significant associations between unfinished material and any form of IPV.

Our findings add to the body of literature documenting the associations of inadequate living conditions and their characteristics with IPV in LMICs. Evidence from DHS data in Nepal suggests that unimproved household water sources elevated women's risk of experiencing physical and emotional IPV [28]. A study conducted in Brazil suggests that 20-59-year-old women living in households with more than two people per bedroom were more likely to report experiencing IPV compared with those living in less crowded housing [29].

However, contrary to our hypothesis, we found two countries, namely Mali and Nigeria, where inadequate living conditions were protective for at least one form of IPV. One potential explanation is that, in these two countries, partners' attitudes toward IPV are an important factor for the occurrence of IPV [30,31], which could reverse or mute the relation between inadequate living conditions and IPV [32]. In Nigeria, the protective effect of women's education levels could be reversed if the community's social norms justify IPV [31]. In Mali, the cash transfer program has been reported to reduce household poverty, but offer limited effects on reducing IPV, as cash might allow men to enact authority [30]. Further research is needed to elucidate the heterogeneity in these findings. Specifically, additional evidence may reveal the mechanisms underlying the negative association between inadequate living conditions and IPV.

The association between living conditions and IPV might be driven by several potential mechanisms: (1) Inadequate living conditions may act as direct stressors. For example, household crowding might lead to stress and depression by making it difficult for women to escape negative interactions $[7,33]$, which are associated with both IPV perpetration and victimization [8,34]. (2) Inadequate living conditions might be directly associated with poor physical health outcomes [6], leading to health-related economic losses, and even household food insecurity [35], which is well established as causing negative emotional well-being among household members [36-38]. (3) Inadequate living conditions might affect occupants' social interactions, which have been recognized as protective factors associated with reduced IPV [39]. The home is commonly regarded as a place for the establishment and maintenance of social ties [40]. Individuals living in an unimproved home might also be reluctant to invite guests into their homes because of the stigma associated with poor housing environments [41], or socially withdraw from others to reduce excessive and unwanted social interactions, which is a prominent feature of a crowded home [42]. Individuals living in crowded homes are less likely to seek support from peers or offer support to peers in need [42].

We observed that rural women were more susceptible to the effects of inadequate living conditions on IPV compared with urban women. Research has reported higher rates of violence among rural couples than among urban couples in SSA [43], potentially owing to the fewer community resources, sparse distribution of law enforcement, and more accepting attitude toward IPV in rural areas [44]. Therefore, rural women are more vulnerable to IPV, which might be exacerbated by inadequate living conditions. We also noted that the association between inadequate living conditions and IPV remained statistically significant only in women with less than secondary education, who were more likely to experience IPV compared with women with secondary or higher education in SSA [43]. A lower education level might create an increased risk of IPV victimization through negative mental 
status, such as low self-esteem, stress, and depression [45], thereby affecting IPV through synergism with inadequate living conditions. In addition, educated people more often have a stable social support network [46], which might mitigate the erosion of social relationships by inadequate living conditions. Thus, policy makers should prioritize rural and less-educated women when gathering resources for housing interventions and IPV screening for families living in inadequate living conditions.

This study has several limitations. First, owing to the cross-sectional design of DHS, our analysis could not derive a causal relation between inadequate living conditions and IPV. Second, the psychological and social mediators that we hypothesized had not been assessed in the DHS; therefore, we could not conduct a mediation analysis. Third, other characteristics of inadequate living conditions such as toxins (e.g., lead, solvents), noise, and insufficient daylight might also result in behavioral disturbances (e.g., aggression and violence) [47]. However, sufficiently detailed measures of these characteristics are not included in the DHS data. Fourth, although the validity of the IPV questionnaire in DHS has been confirmed [18], women might underreport IPV for fear of victimization or stigmatization [48]. Non-differential misclassification generally biases the results to null [49]. Fifth, in some countries, the percentages of inadequate living conditions were high, even above $90 \%$, which could reduce the precision of the estimates. We believe that a metaanalysis would compensate for this limitation by calculating the inverse variance-weighted average of the country-specific estimates. Sixth, our analysis only included married and cohabitating women aged 15-49 years in SSA countries; therefore, the generalization of our findings to other populations should be taken with caution, especially given the cultural differences in IPV disclosure and the subjective acceptability of crowdedness across regions and countries $[48,50]$.

The strength of this study is that we investigated the associations of inadequate living conditions with IPV using multiple nationally representative datasets and analyzed the data in each country in a unified manner. Compared with a single-country study, our work included 25 countries across SSA, and could thus provide a more generalizable estimation. Further, instead of merging data from all countries and conducting a one-stage analysis, we used meta-analyses, which allowed the effect of covariates to vary across countries [51].

Both current WHO guidelines and the technical package for preventing and responding to IPV from the Centers for Disease Control and Prevention (CDC) have primarily focused on legal reform, advocacy of gender equity, and the promotion of the empowerment of women, giving little attention to the living environment [52,53]. Although the CDC's technical package suggests creating a protective environment as a prevention strategy, it does not specify physical living conditions [53]. However, given the relatively small magnitude of the associations found in this study, we do not recommend that scarce resources be shifted away from IPV interventions that have already been shown to be effective in SSA, such as educational meetings or workshops addressing expectations about gender roles and behavior in communication and conflict resolution [54]. Instead, we suggest conducting additional research with a higher level of evidence to provide a better understanding of the effect of living conditions on IPV.

\section{Conclusions}

To the best of our knowledge, this study is the first in SSA to demonstrate the direct associations of inadequate living conditions, especially insufficient space, with three forms of IPV. Specifically, our findings highlighted that the association is most apparent in rural women and women with less than secondary education. Therefore, research with rigorous study designs and measurements of the exposures, outcomes, and mediators is needed to establish a causal link between living conditions and IPV to elucidate the pathways behind this link and design cost-effective IPV screenings and interventions in SSA.

Supplementary Materials: The following are available online at https: / www.mdpi.com/article / 10.3390/ijerph181910138/s1, Table S1: The intimate partner violence (IPV) questionnaire in the Demographic and Health Surveys. Table S2: The Demographic and Health Surveys Program 
classifications of finished/unfinished materials. Table S3: The World Health Organization and United Nations Children's Fund Joint Monitoring Programme for Water Supply, Sanitation, and Hygiene classifications of improved/unimproved facility types. Table S4: Percentage of participants with missing data for each variable of interest in each country. Table S5: Association of inadequate living conditions with any intimate partner violence in 25 countries. Table S6: Association of inadequate living conditions with sexual intimate partner violence in 25 countries. Table S7: Association of inadequate living conditions with emotional intimate partner violence in 25 countries. Table S8: Association of inadequate living conditions with physical intimate partner violence in 25 countries. Table S9: Mutually adjusted associations of inadequate living conditions and its characteristics with intimate partner violence.

Author Contributions: Conceptualization, Y.G.; formal analysis, Y.G.; methodology, Y.G.; software, Y.G.; supervision, H.Z.; validation, Y.G., Y.W. X.M., M.Z. and S.Z.; writing-original draft, Y.G.; writing-review and editing, Y.G. and H.Z. All authors have read and agreed to the published version of the manuscript.

Funding: This research received no external funding.

Institutional Review Board Statement: No human participant work or field research was conducted as part of this secondary data analysis. All data used are publicly available and fully de-identified. Ethical approval for the DHS was provided by individual review boards within each participating country at the time of survey implementation.

Informed Consent Statement: Informed consent was obtained from all subjects involved in the study.

Data Availability Statement: The data presented in this study are openly available at https:// dhsprogram.com/data (accessed on 31 July 2021). Registration is required for access to data.

Conflicts of Interest: The authors declare no conflict of interest.

\section{References}

1. World Health Organization. Global and Regional Estimates of Violence against Women: Prevalence and Health Effects of Intimate Partner Violence and Nonpartner Sexual Violence; World Health Organization: Geneva, Switzerland, 2013.

2. Ellsberg, M.; Arango, D.J.; Morton, M.; Gennari, F.; Kiplesund, S.; Contreras, M.; Watts, C. Prevention of violence against women and girls: What does the evidence say? Lancet 2015, 385, 1555-1566. [CrossRef]

3. Epstein, A.; Bendavid, E.; Nash, D.; Charlebois, E.D.; Weiser, S.D. Drought and intimate partner violence towards women in 19 countries in sub-Saharan Africa during 2011-2018: A population-based study. PLoS Med. 2020, 17, e1003064. [CrossRef]

4. Ekhator-Mobayode, U.E.; Hanmer, L.C.; Rubiano Matulevich, E.C.; Arango, D.J. Effect of Armed Conflict on Intimate Partner Violence: Evidence from the Boko Haram Insurgency in Nigeria; World Bank Group: Washington, DC, USA, 2020.

5. Tusting, L.S.; Bisanzio, D.; Alabaster, G.; Cameron, E.; Cibulskis, R.; Davies, M.; Flaxman, S.; Gibson, H.S.; Knudsen, J.; Mbogo, C.; et al. Mapping changes in housing in Sub-Saharan Africa from 2000 to 2015. Nature 2019, 568, 391-394. [CrossRef]

6. Ezeh, A.; Oyebode, O.; Satterthwaite, D.; Chen, Y.F.; Ndugwa, R.; Sartori, J.; Mberu, B.; Melendez-Torres, G.J.; Haregu, T.; Watson, S.I.; et al. The history, geography, and sociology of slums and the health problems of people who live in slums. Lancet (Lond. Engl.) 2017, 389, 547-558. [CrossRef]

7. Singh, A.; Daniel, L.; Baker, E.; Bentley, R. Housing disadvantage and poor mental health: A systematic review. Am. J. Prev. Med. 2019, 57, 262-272. [CrossRef] [PubMed]

8. Spencer, C.; Mallory, A.B.; Cafferky, B.M.; Kimmes, J.G.; Beck, A.R.; Stith, S.M. Mental health factors and intimate partner violence perpetration and victimization: A meta-analysis. Psychol. Violence 2019, 9, 1-17. [CrossRef]

9. Gibbs, A.; Reddy, T.; Khanyile, D.; Cawood, C. Non-partner sexual violence experience and toilet type amongst young (18-24) women in South Africa: A population-based cross-sectional analysis. Glob. Public Health 2021, 16, 590-596. [CrossRef] [PubMed]

10. Jadhav, A.; Weitzman, A.; Smith-Greenaway, E. Household sanitation facilities and women's risk of non-partner sexual violence in India. BMC Public Health 2016, 16, 1139. [CrossRef] [PubMed]

11. Winter, S.C.; Barchi, F. Access to sanitation and violence against women: Evidence from Demographic Health Survey (DHS) data in Kenya. Int. J. Environ. Health Res. 2016, 26, 291-305. [CrossRef]

12. Panczak, R.; Zwahlen, M.; Spoerri, A.; Tal, K.; Killias, M.; Egger, M. Incidence and risk factors of homicide-suicide in Swiss households: National Cohort study. PLoS ONE 2013, 8, e53714. [CrossRef]

13. Gao, Y.; Mi, X.; Wang, Y.; Zou, S.; Zhou, H. Association between Household Crowding and Violent Discipline and Neglect of Children: Analysis of Multiple Indicator Cluster Surveys in 26 Low- and Middle-Income Countries. Int. J. Environ. Res. Public Health 2021, 18, 1685. [CrossRef]

14. United Nations. World Population Prospects 2019; United Nations Department of Economic and Social Affairs: New York, NY, USA, 2019. 
15. USAID. The Demographic and Health Surveys (DHS) Program. Available online: https://www.dhsprogram.com/ (accessed on 10 June 2021).

16. World Health Organization. Putting Women First: Ethical and Safety Recommendations for Research on Domestic Violence against Women; World Health Organization: Geneva, Switzerland, 2001.

17. Straus, M.A.; Hamby, S.L.; Boney-McCoy, S.U.E.; Sugarman, D.B. The Revised Conflict Tactics Scales (CTS2): Development and preliminary psychometric data. J. Fam. Issues 1996, 17, 283-316. [CrossRef]

18. Hindin, M.; Kishor, S.; Ansara, D.L.; Nilsson, J.E.; Brown, C.; Russell, E.B.; Khamphakdy-Brown, S.; Btoush, R.; Haj-Yahia, M.M.; Serbanescu, F. Intimate partner violence among couples in 10 DHS countries: Predictors and health outcomes. J. Interpers. Violence 2008, 23, 1654-1663.

19. UN-HABITAT. The Challenge of Slums: Global Report on Human Settlements 2003 (Revised and Updated Version 2010); UN-HABITAT: Nairobi, Kenya, 2010.

20. Tusting, L.S.; Gething, P.W.; Gibson, H.S.; Greenwood, B.; Knudsen, J.; Lindsay, S.W.; Bhatt, S. Housing and child health in sub-Saharan Africa: A cross-sectional analysis. PLoS Med. 2020, 17, e1003055. [CrossRef]

21. Assaf, S.; Juan, C. Stunting and anemia in children from urban poor environments in 28 low and middle-income countries: A meta-analysis of demographic and health survey data. Nutrients 2020, 12, 3539. [CrossRef]

22. Gao, Y.; Zhang, L.; Kc, A.; Wang, Y.; Zou, S.; Chen, C.; Huang, Y.; Mi, X.; Zhou, H. Housing environment and early childhood development in sub-Saharan Africa: A cross-sectional analysis. PLoS Med. 2021, 18, e1003578. [CrossRef] [PubMed]

23. UNICEF; WHO. Progress on Household Drinking Water, Sanitation and Hygiene 2000-2017: Special Focus on Inequalities; UNICEF and WHO: New York, NY, USA, 2019.

24. The DHS Program. Wealth Index Construction. Available online: https://dhsprogram.com/topics/wealth-index/Wealth-IndexConstruction.cfm (accessed on 17 July 2021).

25. Higgins, J.P.T.; Thompson, S.G.; Deeks, J.J.; Altman, D.G. Measuring inconsistency in meta-analyses. BMJ 2003, 327, 557-560. [CrossRef] [PubMed]

26. DerSimonian, R.; Laird, N. Meta-analysis in clinical trials. Control. Clin. Trials 1986, 7, 177-188. [CrossRef]

27. Jakobsen, J.C.; Gluud, C.; Wetterslev, J.; Winkel, P. When and how should multiple imputation be used for handling missing data in randomised clinical trials-A practical guide with flowcharts. BMC Med Res. Methodol. 2017, 17, 162. [CrossRef]

28. Choudhary, N.; Brewis, A.; Wutich, A.; Udas, P.B. Sub-optimal household water access is associated with greater risk of intimate partner violence against women: Evidence from Nepal. J. Water Health 2020, 18, 579-594. [CrossRef] [PubMed]

29. Anacleto, A.J.; Njaine, K.; Longo, G.Z.; Boing, A.F.; Peres, K.G. Prevalence of intimate partner violence and associated factors: A population-based study in Lages, Santa Catarina State, Brazil, 2007. Cad. Saude Publica 2009, 25, 800-808. [CrossRef] [PubMed]

30. Lees, S.; Kyegombe, N.; Diatta, A.; Zogrone, A.; Roy, S.; Hidrobo, M. Intimate Partner relationships and gender norms in Mali: The scope of cash transfers targeted to men to reduce intimate partner violence. Violence Against Women 2020, 27, 447-469. [CrossRef] [PubMed]

31. Benebo, F.O.; Schumann, B.; Vaezghasemi, M. Intimate partner violence against women in Nigeria: A multilevel study investigating the effect of women's status and community norms. BMC Womens Health 2018, 18, 136. [CrossRef] [PubMed]

32. Sugarman, D.; Frankel, S. Patriarchal ideology and wife-assault: A meta-analytic review. J. Fam. Violence 1996, 11, 13-40. [CrossRef]

33. Regoeczi, W.C. When context matters: A multilevel analysis of household and neighbourhood crowding on aggression and withdrawal. J. Environ. Psychol. 2003, 23, 457-470. [CrossRef]

34. Caetano, R.; Ramisetty-Mikler, S.; Caetano Vaeth, P.A.; Harris, T.R. Acculturation stress, drinking, and intimate partner violence among Hispanic couples in the U.S. J. Interpers. Violence 2007, 22, 1431-1447. [CrossRef] [PubMed]

35. Brewis, A.; Workman, C.; Wutich, A.; Jepson, W.; Young, S. Household water insecurity is strongly associated with food insecurity: Evidence from 27 sites in low- and middle-income countries. Am. J. Hum. Biol. Off. J. Hum. Biol. Counc. 2020, 32 , e23309. [CrossRef]

36. Bruening, M.; Dinour, L.M.; Chavez, J.B.R. Food insecurity and emotional health in the USA: A systematic narrative review of longitudinal research. Public Health Nutr. 2017, 20, 3200-3208. [CrossRef] [PubMed]

37. Diamond-Smith, N.; Conroy, A.A.; Tsai, A.C.; Nekkanti, M.; Weiser, S.D. Food insecurity and intimate partner violence among married women in Nepal. J. Glob. Health 2019, 9, 010412. [CrossRef]

38. Ribeiro-Silva Rde, C.; Fiaccone, R.L.; Barreto, M.L.; Santana, M.L.; dos Santos, S.M.; da Conceição-Machado, M.E.; Aliaga, M.A. The association between intimate partner domestic violence and the food security status of poor families in Brazil. Public Health Nutr. 2016, 19, 1305-1311. [CrossRef]

39. Wright, E.M. The relationship between social support and intimate partner violence in neighborhood context. Crime Delinq. 2012, 61, 1333-1359. [CrossRef]

40. Bronfenbrenner, U.; Evans, G.W. Developmental science in the 21st century: Emerging questions, theoretical models, research designs and empirical findings. Soc. Dev. 2000, 9, 115-125. [CrossRef]

41. Burdette, A.M.; Hill, T.D.; Hale, L. Household disrepair and the mental health of low-income urban women. J. Urban Health 2011, 88, 142-153. [CrossRef]

42. Evans, G.W.; Lepore, S.J. Household crowding and social support: A quasiexperimental analysis. J. Pers. Soc. Psychol. 1993, 65, 308-316. [CrossRef] 
43. Nabaggala, M.S.; Reddy, T.; Manda, S. Effects of rural-urban residence and education on intimate partner violence among women in Sub-Saharan Africa: A meta-analysis of health survey data. BMC Womens Health 2021, 21, 149. [CrossRef]

44. Edwards, K.M. Intimate Partner Violence and the Rural-Urban-Suburban Divide Myth or Reality? A Critical Review of the Literature. Trauma Violence Abus. 2015, 16, 359-373. [CrossRef] [PubMed]

45. ten Kate, J.; de Koster, W.; van der Waal, J. Why are depressive symptoms more prevalent among the less educated? The relevance of low cultural capital and cultural entitlement. Sociol. Spectr. 2017, 37, 63-76. [CrossRef]

46. Ferlander, S. The importance of different forms of social capital for health. Acta Sociol. 2007, 50, 115-128. [CrossRef]

47. Evans, G.W. The built environment and mental health. J. Urban Health 2003, 80, 536-555. [CrossRef]

48. Garcia-Moreno, C.; Jansen, H.A.; Ellsberg, M.; Heise, L.; Watts, C.H. Prevalence of intimate partner violence: Findings from the WHO multi-country study on women's health and domestic violence. Lancet (Lond. Engl.) 2006, 368, 1260-1269. [CrossRef]

49. Jurek, A.M.; Greenland, S.; Maldonado, G.; Church, T.R. Proper interpretation of non-differential misclassification effects: Expectations vs observations. Int. J. Epidemiol. 2005, 34, 680-687. [CrossRef]

50. Lauster, N.; Tester, F. Culture as a problem in linking material inequality to health: On residential crowding in the Arctic. Health Place 2010, 16, 523-530. [CrossRef] [PubMed]

51. Basagaña, X.; Pedersen, M.; Barrera-Gómez, J.; Gehring, U.; Giorgis-Allemand, L.; Hoek, G.; Stafoggia, M.; Nieuwenhuijsen, M.J.; Brunekreef, B.; Slama, R. Analysis of multicentre epidemiological studies: Contrasting fixed or random effects modelling and meta-analysis. Int. J. Epidemiol. 2018, 47, 1343-1354. [CrossRef] [PubMed]

52. World Health Organization. Understanding and Addressing Violence against Women: Intimate Partner Violence; World Health Organization: Geneva, Switzerland, 2012.

53. Centers for Disease Control and Prevention. Preventing Intimate Partner Violence across the Lifespan: A Technical Package of Programs, Policies, and Practices; Centers for Disease Control and Prevention: Atlanta, GA, USA, 2017.

54. Wagman, J.A.; Gray, R.H.; Campbell, J.C.; Thoma, M.; Ndyanabo, A.; Ssekasanvu, J.; Nalugoda, F.; Kagaayi, J.; Nakigozi, G.; Serwadda, D.; et al. Effectiveness of an integrated intimate partner violence and HIV prevention intervention in Rakai, Uganda: Analysis of an intervention in an existing cluster randomised cohort. Lancet Glob. Health 2015, 3, e23-e33. [CrossRef] 